\title{
Squamous Odontogenic Tumor of the Mandible: A Case Report Demonstrating Immunoexpression of Notch1, 3, 4, JAGGED1 AND DELTA1
}

\author{
C. H. Siar ${ }^{1}$, K. Nakano ${ }^{2}$, K. H. Ng${ }^{3}$, M. Tomida ${ }^{4}$, H. Nagatsuka ${ }^{5}$, T. Kawakami ${ }^{2}$
}

\begin{abstract}
${ }^{1}$ Department of Oral Pathology, Oral Medicine and Periodontology, Faculty of Dentistry, University of Malaya, Kuala Lumpur, Malaysia,
${ }^{2}$ Hard Tissue Pathology Unit, Matsumoto Dental University Graduate School of Oral Medicine, Shiojiri, Japan, ${ }^{3}$ Formerly Unit of Stomatology, Cancer Research Centre, Institute for Medical Research, Jalan Pahang, Kuala Lumpur, Malaysia, ${ }^{4}$ Department of Oral Physiology, Matsumoto Dental University School of Dentistry, Shiojiri, Japan,

${ }^{5}$ Department of Oral Pathology and Medicine, Graduate School of Medicine, Dentistry and Pharmaceutical Sciences, Okayama University, Okayama, Japan
\end{abstract}

\begin{abstract}
Background: Squamous odontogenic tumor (SOT) is a rare benign odontogenic epithelial neoplasm. A slowgrowing painless expansive swelling is the common presenting symptom. Histopathologically, SOT can be easily misdiagnosed as an acanthomatous ameloblastoma. Although Notch receptors and ligands have been shown to play a role in cell fate decisions in ameloblastomas, the role of these cell signaling mole-
\end{abstract} cules in SOT is unknown.

Case report: This paper describes a case of SOT affecting the anterior mandible of a 10 -year-old Indian female. The patient was treated by local surgical excision and there has been no follow-up clinical record of recurrence 5 years after primary treatment. Histopathological examination revealed a solid, locally-infiltrative neoplasm composed of bland-looking squamatoid islands scattered in a mature fibrous connective tissue stroma and the diagnosis was SOT. Immunohistochemical evaluation showed positive reactivity of varying intensity in the neoplastic epithelial cells for Notch1, Notch3, Notch4, and their ligands Jagged1 and Delta1. Expression patterns showed considerable overlap. No immunoreactivity was detected for Notch2 and Jagged2.

Conclusions: Present findings suggest that Notch receptors and their ligands play differential roles in the cytodifferentiation of SOT.

Key words: solitary odontogenic tumor, Notch signaling, immunohistochemistry, cytodifferentiation

\section{INTRODUCTION}

Squamous odontogenic tumor (SOT) is a rare tumor with less than 50 cases reported [1]. It was first described as a distinct entity by Pullon et al. in 1975 [2]. The aetiopathogenesis of this benign locally-invasive odontogenic epithelial neoplasm is unclear. Clinicopathologically, three main types are identified: intraosseous [1], mural (mural SOT-like proliferations in cyst) [3] and extraosseous forms [4]. SOT affects a wide age range, shows a slight male preponderance and occurs more frequently in the mandible [1]. Aggressive [5] and multifocal [6] variants have been reported.
Histopathologically it is composed of islands of welldifferentiated non-keratinizing squamous epithelium surrounded by a mature fibrous connective tissue [1]. There is no cellular atypia. In the epithelial islands, cystic degeneration as well as calcification may occur. Invasion into cancellous bone may be present [7].

Mammalian Notch is a four-member family of receptors (Notch1-4) that mediates short-range events [8, 9]. The Notch receptor is a single transmembrane protein containing distinct structural extracellular and intracellular domains. The structure of the four Notch receptors is highly homologous with only some differences in these domains. Notch signaling pathway is activated when cell surface-anchored ligands (Jagged1, Jagged2, Delta1, Delta3 and Delta4) from neighboring cells bind the receptors and trigger the proteolytic cleavage of Notch receptors. The activation of Notch signaling pathway leads to different outcomes ranging from control of proliferation to apoptosis, differentiation, maintenance of stemness and cell fate decision [9]. Deregulation of Notch signaling has been implicated in some genetic diseases and tumorigenesis [10]. Notch signaling in a variety of tumors can be either oncogenic or tumor suppressive, depending on the specific cellular context, also in odontogenic neoplasms [11-13].

The potential role for Notch signaling pathway in the development and cytodifferentiation of odontogenic neoplasms has gained attention only recently. In others [14] and our studies [15-17], Notch expression was observed in plexiform and follicular ameloblastoma [4, 15], ameloblastic carcinoma [16] and ameloblastic fibroma [17] but not in the odontogenic myxoma [17]. A search of the English language literature disclosed that Notch signaling activity in SOT is not known. In this report, the expression patterns of Notch1-4 and their ligands, Jagged1, Jagged2 and Delta1 in a case of SOT are presented and the significance of these findings speculated.

\section{CASE REPORT}

\section{Clinical SUMmary}

A 10-year-old Indian female patient was seen for a complaint of a slowly-enlarging, non-tender swelling of 
unknown duration in her anterior mandible. No further clinical or radiographic information was available as to the presentation of this lesion in the jaw. A pre-operative diagnosis of ossifying fibroma was made. The lesion was surgically excised under general anesthesia, and submitted for histopathological examination. No follow-up information was available as to the outcome of the patient five years after primary treatment.

\section{HistopathoLOGY}

Microscopic examination of the lesional area disclosed a solid, locally-infiltrative, benign odontogenic epithelial neoplasm. It was composed of bland-looking islands of well-differentiated squamous epithelium set against a mature fibrous connective tissue stroma (Fig. 1). These tumor islands did not show any evidence of peripheral columnar cells, reversal nuclear polarity or central stellate reticulum-like cells. Cellular atypia was absent. There was central keratinization and cystic degeneration. Foci of dystrophic calcifications and occasional clear cell clusters were noted. These histopathological findings led us to daiagnose the lesion to be SOT.

\section{IMMUNOHISTOCHEMISTRY}

The immunohistochemical detection of Notch receptors and ligands was performed using the Envision technique as previously described [14]. Primary antibodies used are detailed in Table 1. Stromal endothelium and fibroblasts served as internal positive controls while negative controls were performed by substituting the primary antibody with phosphate-buffered saline.

SOT showed positive expression for Notch1, Notch3 and Notch4 in the well-differentiated squamous epithelial islands, central keratinization and cystic degeneration (Fig. 2). Notch2 was not detected. Expression for Jagged1 was moderate while that for Delta1 was weak within the neoplastic epithelium. Jagged2 was consistently absent. Clear cell nests and dystrophic calcific foci showed similar expression patterns (Fig.3). Stromal endothelium and fibroblasts

Table 1. Details of primary antibodies used in this examination.

\begin{tabular}{llll}
\hline Antibody & Manufacturer & Product & Dilution \\
\hline Notch1 & Abcam & Rabbit polyclonal & $1: 500$ \\
Notch2 & R\&D System & Goat polyclonal & $1: 500$ \\
Notch3 & Abcam & Rabbit polyclonal & $1: 500$ \\
Notch4 & Abcam & Rabbit polyclonal & $1: 500$ \\
Jagged1 & Abcam & Goat polyclonal & $1: 500$ \\
Jagged2 & Abcam & Rabbit polyclonal & $1: 500$ \\
Delta1 & R\&D System & Mouse monoclonal & $1: 200$ \\
\hline
\end{tabular}

Table 2. Expression of Notch signaling molecules in odontogenic neoplasms as examined by ISH and IHC.

\begin{tabular}{|c|c|c|c|c|c|c|c|}
\hline Studies & Notch1 & Notch2 & Notch3 & Notch4 & Jagged1 & Jagged2 & Delta1 \\
\hline \multicolumn{8}{|l|}{ Ameloblastoma $(n=22)[14]$} \\
\hline Peripheral cells & - & + & - & NA & $-/+$ & NA & $-/+$ \\
\hline Central cells & $+/++$ & ++ & $+/++$ & NA & + & NA & $+/++$ \\
\hline Keratinizing cells & - & - & - & NA & - & NA & - \\
\hline Granular cells & - & - & - & NA & - & NA & - \\
\hline Stromal cells & $+/++$ & $+/++$ & $+/++$ & NA & $+/++$ & NA & $+/++$ \\
\hline \multicolumn{8}{|c|}{ Ameloblastic carcinoma $(n=1)[16]$} \\
\hline Peripheral cells & + & NA & NA & NA & NA & NA & NA \\
\hline Central cells & +++ & NA & NA & NA & NA & NA & NA \\
\hline \multicolumn{8}{|c|}{ Ameloblastic fibroma $(n=1)[17]$} \\
\hline Peripheral cells & + & NA & NA & NA & NA & NA & NA \\
\hline Central cells & +++ & NA & NA & NA & NA & NA & NA \\
\hline Dental papilla-like cells & +++ & NA & NA & NA & NA & NA & NA \\
\hline \multicolumn{8}{|c|}{ Odontogenic myxoma $(\mathrm{n}=1)$} \\
\hline Dental papilla-like cells & - & NA & NA & NA & NA & NA & NA \\
\hline \multicolumn{8}{|c|}{ Squamous odontogenic tumor $(\mathrm{n}=1)^{*}$} \\
\hline Peripheral cells & ++ & - & + & +++ & $+/++$ & - & $-/+$ \\
\hline Central cells & ++ & - & + & +++ & $+/++$ & - & $-/+$ \\
\hline Keratinizing cells & ++ & - & + & +++ & $+/++$ & - & $-/+$ \\
\hline Cystic degeneration & ++ & - & + & +++ & $+/++$ & - & $-/+$ \\
\hline Clear cells & ++ & - & + & +++ & $+/++$ & - & $-/+$ \\
\hline Dystrophic calcifications & ++ & - & + & +++ & $+/++$ & - & $-/+$ \\
\hline
\end{tabular}

\footnotetext{
* Present study; NA: Not available; $(-)$ :negative; $(+)$ : mild; $(++)$ : moderate; $(+++)$ :strong immunopositivity
} 

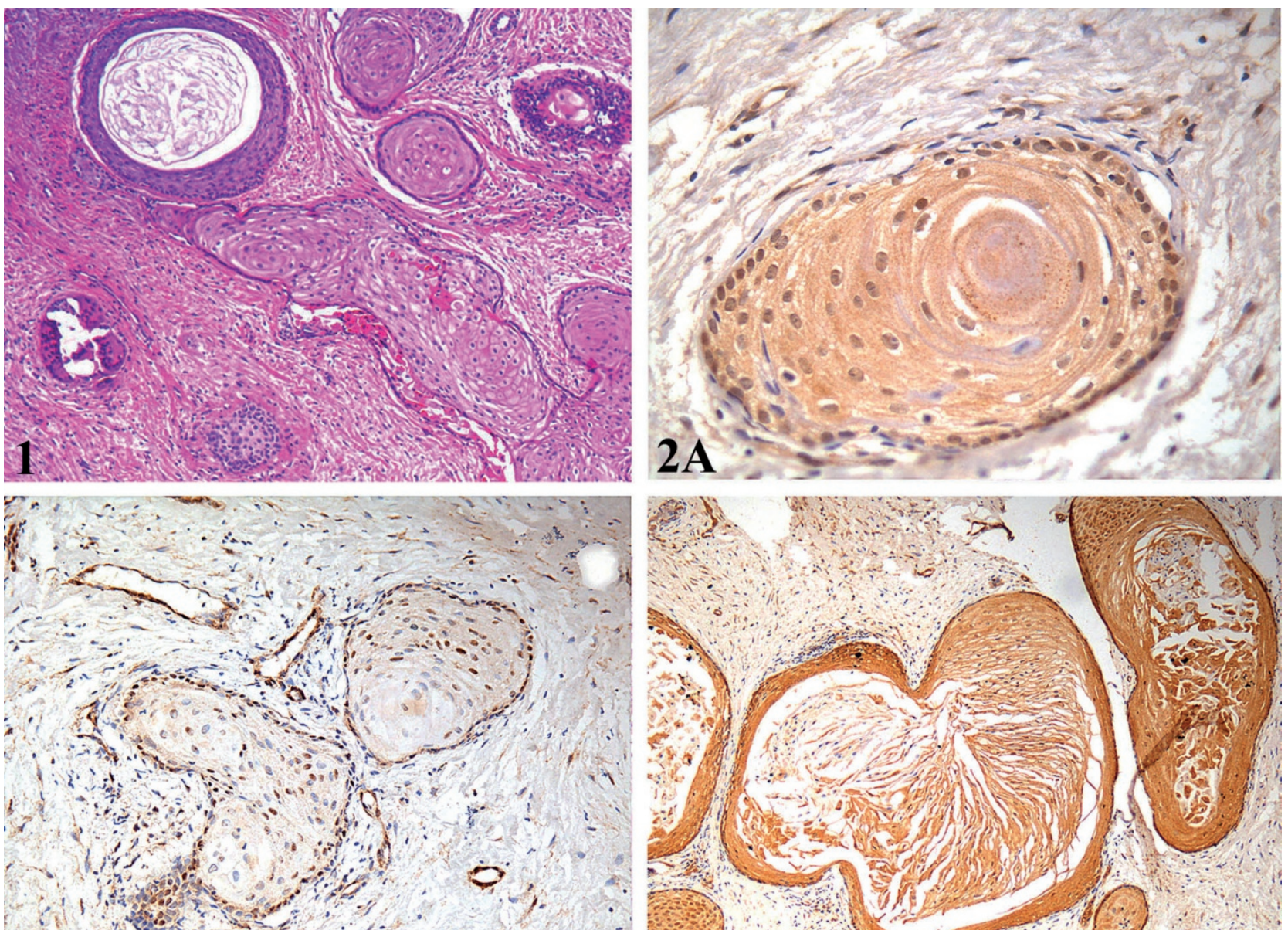

2B

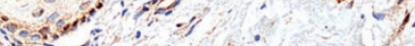
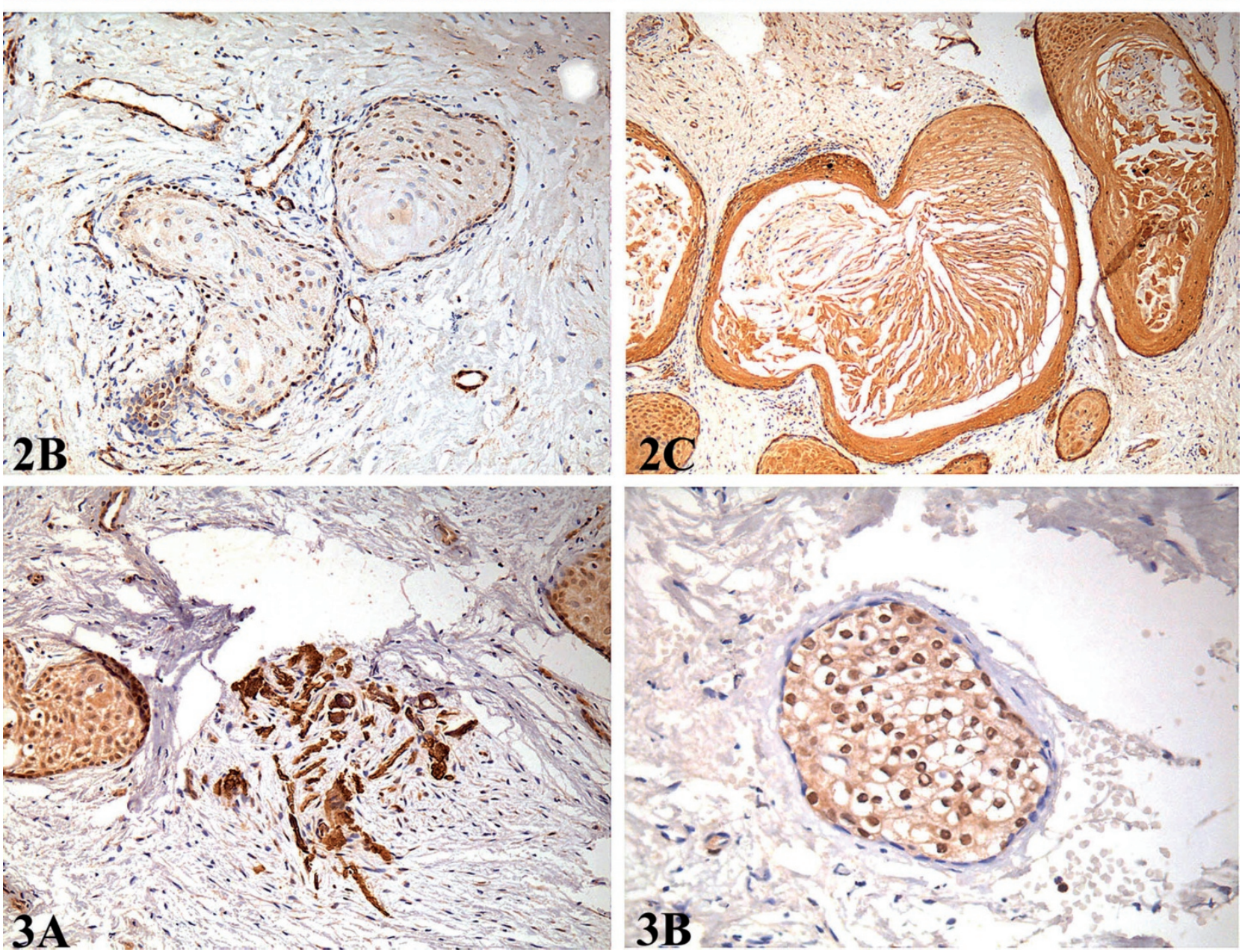

Fig. 1. Photomicrograph of SOT showing lesional area composed of bland-looking islands of well-differentiated squamous epithelium set against a mature fibrous connective tissue stroma. Central cystic degeneration is present. (H\&E, original magnification, $\mathrm{x} 100)$

Fig. 2. Immunohistochemical staining for Notch receptors: A, Notch1 shows moderate expression in a squamous island with central keratinization; B, Notch3 weak expression in squamous tumor islands but moderate to strong in vascular endothelium and stromal fibroblasts; and C, Notch4 overexpression in epithelial keratinizing cysts. (original magnification, A, x400; B, x200; C, $\mathrm{x} 100)$

Fig. 3. Immunohistochemical staining for Notch ligands: A, Jagged1 shows moderate to strong expression in squamous islands and in a focus of dystrophic calcification; and B, Delta1 weak expression in a clear cell cluster. (original magnification, A, x200; $\mathrm{B}, \mathrm{x} 400)$.

were variably positive for Notch receptors and ligands. Furthermore, there were some Notch1,3,4 positive cells scattered in the stromal connective tissue.
Staining intensity of SOT was analyzed according to the criteria of published studies $[14,16,17]$ (Table 2) where expression results of immunohistochemistry 
(IHC) and in situ hybridization (ISH) in the neoplastic epithelium were quantified as negative (-) when no cells were stained, mild $(+)$ when less than $25 \%$ cells stained positive, moderate $(++)$ for $25-50 \%$ positive cells, and strong $(+++)$ for greater than $50 \%$ positive.

\section{DisCUSSION}

SOT is classified as a benign, locally-infiltrative odontogenic epithelial neoplasm with three possible sources of origin depending on its location. Intraosseous SOT putatively originates from the cell rests of Malassez whereas its peripheral counterpart arises from the dental lamina remnants (glands of Serres) or the gingival surface epithelium [18]. SOT must be distinguished from other intraosseous neoplasms notably ameloblastoma and primary intraosseous squamous cell carcinoma. Histopathologically, tumor islands in SOT consisted of well-differentiated squamous epithelium without peripheral palisading unlike those in the classic ameloblastoma which characteristically exhibits a peripheral layer of pre-ameloblasts and central stellate reticulum-like cells $[3,18]$. Primary intraosseous squamous cell carcinoma can be ruled out on grounds of absence of cytological features of malignancy in the tumor islands of SOT $[3,7]$. In the present case all these aspects were considered before arriving at a diagnosis of SOT.

The Notch family of receptors has been characterized as critical determinants of cell fate in a variety of organisms [8-10]. Notch receptors participate in cell fate decisions by the process of lateral inhibition or inductive signaling. In the developing tooth, Notch receptors and ligands have been found to be expressed in dental epithelium and/or ectomesenchyme, suggesting that Notch signaling may regulate odontogenesis [19]. It is known that the morphological characteristics and inductive relationship between various parts of the developing tooth germ are reproduced to a greater or lesser extent in many of the tumors and tumor-like lesions of the odontogenic apparatus [1]. In the light of this, the potential role of the Notch signaling pathway in the proliferation and cellular differentiation of some of these odontogenic neoplasms was examined. Notch1, 2 and 3, Jagged1 and Delta1 were detected in the central and peripheral cells of the follicular and plexiform ameloblastoma but were absent in areas exhibiting keratinization and granular cell differentiation, and in stromal cells (Table 2) [14]. These findings led the authors to suggest that Notch signaling does not play an oncogenic role in the tumorigenesis of odontogenic epithelium but might contribute to the control of neoplastic cell differentiation and suppress neoplastic cell proliferation in odontogenic epithelium [14]. In the ameloblastic carcinoma, Notch1 was expressed by most neoplastic epithelial cells including small numbers of mitoses, and these observations led to the suggestion that Notch1 plays some roles in the cytological differentiation or acquisition of tissue specific characteristics and may contribute to cell cycle arrest in these neoplastic cells $[11,16]$. In the case of ameloblastic fibroma, Notch1 activity was detected in the peripheral and central cells of tumor nests and strands as well as in the dental papilla-like stromal cells, and these findings sug- gest that Notch signaling might be involved in the specific cell differentiation of the epithelial nests of this neoplasm [17]. During odontogenesis, Notch1 transcriptions were seen in the dental mesenchyme after the cap stage [19]. For the odontogenic myxoma, Notch signaling activity was absent and this was attributed to the fact that the mesenchymal tissue in this neoplasm is in a less advanced stage of differentiation than the dental papilla-like tissue in the ameloblastic fibroma [17].

In the current study, Notch1, 3 and 4, Jagged1 and Delta1 were expressed by the peripheral and central cells of the tumor islands in the SOT as well as in areas of keratinization, cystic degeneration, clear cell differentiation and dystrophic calcification foci. Notch2 and Jagged 2 were consistently absent. These preliminary findings suggest that Notch signaling may be involved in the cellular differentiation of SOT. It is further observed that ameloblastoma and SOT are both benign neoplasms of odontogenic epithelium without odontogenic ectomesenchymal participation but their Notch expression patterns differ. We believed that these differences may be due to their different stages of cellular differentiation. In the ameloblastoma tumor epithelium, the peripheral cells resembled the preameloblasts while the central cells resembled the stellate reticulum of the developing tooth germ after cap stage [14]. In the SOT, the tumor epithelium has a squamous characteristic. These differences in Notch expression patterns may be related to the different functional activities of these cell signaling molecules during the cellular differentiation of the ameloblastoma and SOT.

In summary, a case of SOT is reported here and its Notch immunoexpression profile defined. As a wide range of neoplasms including odontogenic neoplasms occurs in the oral and craniofacial regions research on cell differentiation phenomenon and cell signaling factors is currently ongoing [11-17, 20-25]. Studies on larger series of SOT are also recommended to help refine the role of these signaling molecules in the development of this neoplasm.

Acknowledgments: This research was supported jointly by the University of Malaya Research Grant FS170/2008C and Grant-in Aid for Scientific Research (C) (20592349) from the Japan Society for the Promotion of Science.

\section{REFERENCES}

1. Reichart PA. Squamous odontogenic tumour. In: Bames L, Eveson JW, Reichart P, Sidransky D (eds) World Health Organization Classification of Tumours: Pathology and genetics of tumours of the head and neck. 301, 2005, IARC Press, Lyon, France.

2. Pullon PA, Shafer WG, Elzay RP, Kerr DA, Corio RL. Squamous odontogenic tumor: Report of six cases of a previously undescribed lesion. Oral Surg Oral Med Oral Pathol 1975; 40: 616-630.

3. Oliveira JA, Costa IM. Squamous odontogenic tumor-like proliferations (SOT-LP) versus intraosseous squamous cell carcinoma in residual cyst. J Oral Maxillofac Surg 2006; 64: 1325

4. Baden E, Doyle J, Mesa M, Fabie M, Lederman D, Eichen M. Squamous odontogenic tumor: Report of three cases including the first extraosseous case. Oral Surg Oral Med Oral Pathol 1993; 75: 733-738. 
5. Ruhin B, Raoul G, Kolb F, Casiraghi O, Lecomte-Houcke M, Ghoul S, Auriol M and Ferri J. Aggressive maxillary squamous odontogenic tumour in a child: histological dilemma and adaptive surgical behaviour. Int J Oral Maxillofac Surg 2007; 36: 864-866.

6. Leider AS, Jonker LA, Cook HE. Multicentric familial squamous odontogenic tumor. Oral Surg Oral Med Oral Pathol 1989; 68: 175-181.

7. Kim K, Mintz SM, Stevens J. Squamous odontogenic tumor causing erosion of the lingual cortical plate of the mandible: a report of 2 cases. J Oral Maxillofac Surg. 2007; 65: 1227-1231.

8. Miele L. Notch signaling. Clin Cancer Res 2006; 12: 10741079.

9. Artavanis-Tsakonas S, Rand MD, Lake RJ. Notch signaling: Cell fate control and signal integration in development. Science 1999; 284: 770-776.

10. Leong KG, Karsan A. Recent insights into the role of Notch signaling in tumorigenesis. Blood 2006; 107: 2223 2233.

11. Nakano K, Nagatsuka H, Tsujigiwa H, Gunduz M, Katase $\mathrm{N}$, Siar $\mathrm{CH}$ and Kawakami T. Immunohistochemical characteristics of odontogenic neoplasms and their physiological counterparts. J Hard Tissue Biol 2008; 17: 79-90.

12. Kawakami $\mathrm{T}$ and Nagatsuka $\mathrm{H}$. Cell differentiation of neoplastic cells originating in the oral and craniofacial regions. pp 1-56, Nova Science Publishers, Inc. New York, 2009.

13. Kawakami T, Nagatsuka H, Nakano K, Shimizu T, Tsujigiwa $H$, Hasegawa $H$ and Nagai N. Chapter 1: Cell differentiation of neoplastic cells originating in the oral and craniofacial regions. In Ivanova LB ed., Cell Differentiation Research Developments, p1-30, Nova Science Publishers, Inc. New York, 2008.

14. Kumamoto H, Ohki K, Ooya K. Expression of notch signaling molecules in ameloblastomas. J Oral Pathol Med 2008; 37: 228-234.

15. Siar $\mathrm{CH}, \mathrm{Ng} \mathrm{KH}$, Ariff Z, Muraki E, Shimizu T, Tsujigiwa $\mathrm{H}$, Nagatsuka $\mathrm{H}$, Nagai $\mathrm{N}$ and Kawakami T. A case report of ameloblastoma of the mandible with examination of Notch signaling. Oral Med Pathol 2006; 11: 35-39.

16. Nakano K, Siar CH, Tsujigiwa H, Nagatsuka H, Nagai N, Kawakami T. Notch signaling in benign and malignant ameloblastic neoplasms. Eur J Med Res 2008; 13: 476480.

17. Nakano K, Chelvanayagam P, Born K, Siar CH, Ng KH, Nagatsuka $\mathrm{H}$ and Kawakami T. A study of recurrent giant odontogenic myxoma of the mandible with immunohistochemical examination of Notch. Oral Med Pathol 2008; 12: $53-56$.
18. Tatemoto Y, Okada Y, Mori M. Squamous odontogenic tumor: immunohistochemical identification of cytokeratins. Oral Surg Oral Med Oral Pathol 1989; 67: 63-67.

19. Mitsiadis TA, Regaudiat L, Gridley T. Role of Notch signaling pathway in tooth morphogenesis. Arch Oral Biol 2005; 50: 137-140.

20. Chuah KS, Siar CH, Nakano K, Nagatsuka H, KhooSP, $\mathrm{Ng} \mathrm{KH}$ and Kawakami T. Wingless-type protein-1 (Wnt1) expression in primary conventional and unicystic ameloblastomas and their recurrent tumors. J Hard Tissue Biol 2009; 18: 63-70.

21. Nagatsuka H, Katase N, Pwint HP, Tsujigiwa H, Siar CH, Nakajima M, Naomoto Y, Tamamura R, Kawakami T and Gunduz M. Heparanase and its related molecules in odontogenic tumors. Oral Med Pathol 2009; 13: 81-89.

22. Han PP, Nagatsuka H, Tamamura R, Katase N, Bernard M, Hu H, Takagi S, Ishida N, Nakano K, Kawakami T and Gunduz M. Role of Heparanase in the release of heparin sulphate binding growth factors in of odontogenic tumors. J Hard Tissue Biol 2007; 16: 36-41.

23. Inoue M, Nagatsuka $\mathrm{H}$, Tamamura R, Siar $\mathrm{CH}$, Tsujigiwa H, Borkosky S, Fujii M and Setsu K. Localization of oxytalan fiber, type III collagen and BMP family in conventional and desmoplastic ameloblastoma. J Hard Tissue Biol 2008; 17: 23-30.

24. Han PP, Tamamura R, Katase N, Fujii E, Okauchi M, Jin T, Siar CH and Nagatsuka H. Differential distribution of type IV collagen $\alpha 1$ to $\alpha 6$ chains suggests distinct molecular interaction between the epithelial and mesenchymal components of benign odontogenic tumors. J Hard Tissue Biol 2006; 15: 46-53.

25. Heikinheimo K, Mori K, Nagatsuka H and Happonen RP. Transforming growth factor beta (TGF- $\beta$ ) gene family members in developing and neoplastic odontogenic tissues. J Hard Tissue Biol 2006; 15: 1-5.

Received: September 30, 2009 / Accepted: October 14, 2009

Address for correspondence:

Keisuke Nakano, DDS, PhD,

Hard Tissue Pathology Unit

Matsumoto Dental University Graduate School

of Oral Medicine

1780 Hirooka-Gobara

Shiojiri, 399-0781 Japan

Phone and Fax: $\quad+81-(0) 263-51-2035$

E-mail: keisuke1@po.mdu.ac.jp 